\title{
Ocular basal cell carcinoma: a brief literature review of clinical diagnosis and treatment
}

This article was published in the following Dove Press journal:

OncoTargets and Therapy

8 May 2017

Number of times this article has been viewed

Yingyun Shi

Renbing Jia

Xianqun Fan

Department of Ophthalmology, Shanghai Ninth People's Hospital, Shanghai, People's Republic of China

\begin{abstract}
Basal cell carcinoma (BCC) is a common malignant tumor throughout the world. One of the known risk factors of BCC is intense exposure to ultraviolet radiation. More than $50 \%$ of BCCs of the eyelid initially occur on the lower lid. The gold standard of diagnosis of BCC is histopathology. Treatment options for BCC consist of surgery, vismodegib, radiotherapy and imiquimod. Surgical excision using Mohs micrographic surgery or wide surgical excision with frozen section margin control is the first consideration for treatment of periocular BCC. Eyelid reconstruction should be carefully considered as both function and esthetic outcome in patients are important after clear excision of tumors. Exenteration is considered in the case of extensive orbital invasion or high-risk aggressive tumors in order to reduce the rate of recurrence.
\end{abstract}

Keywords: basal cell carcinoma, eyelid, orbit, surgery, vismodegib, radiotherapy, imiquimod

\section{Introduction}

Basal cell carcinoma (BCC) is the most common cancer in the world. Eighty percent of BCCs occur in the head and neck region, of which $20 \%$ occur on the eyelids. BCC constitutes $90 \%$ of malignant eyelid tumors, with a slight male preponderance. ${ }^{1} \mathrm{BCC}$ with orbital invasion is uncommon, with a reported incidence of only $1.6 \%-2.5 \%{ }^{2}$ The age of tumor emergence is typically $60-80$ years. Although metastasis is rare, $\mathrm{BCC}$ of the eyelids has a high risk of recurrence. Recurrent BCCs are often associated with primary tumors of an aggressive subtype, and they usually have a worse overall prognosis than the primary tumor. BCC is usually not fatal, but if it is not diagnosed for a long time, the function and the appearance of the eyelid will be destroyed. ${ }^{3-6}$ Therefore, early diagnosis and surgery promise better treatment outcomes including functionality and esthetic outcomes.

\section{Epidemiology and etiology of BCC}

The incidence of BCC is higher in more equatorial latitudes than in polar latitudes. ${ }^{7}$ The intermittent intense exposure to ultraviolet (UV) radiation is one of the most important known risk factors of BCC. Short-wavelength UVB radiation (290-320 nm, sunburn rays) plays a more important role in $\mathrm{BCC}$ formation than long-wavelength UVA radiation (320-400 nm, tanning rays). UVB radiation damages DNA and its repair system, and changes the immune system resulting in progressive genetic alterations that lead to the formation of neoplasms. Mutations in the TP53 tumor-suppressor gene induced by UV have been found in about $50 \%$ of BCC cases. The mutations which play a significant role in cutaneous carcinogenesis activate hedgehog intercellular signaling pathway genes, including patched (Ptch), sonic hedgehog and smoothened. Ptch-1 mutations promote the development of eyelid BCC. ${ }^{8}$ de Gruijl et al found that long-term 
exposure to UV radiation may induce Ptch-1 mutations and thus promote the development of BCC. ${ }^{9}$ Other risk factors for the development of BCC include sun bed use, family history of skin cancers, immunosuppression, previous radiotherapy and chronic exposure to toxic substances. ${ }^{7}$

Lim et al found that a high incidence of BCC and a larger BCC size were associated with a low socioeconomic status, which corresponds to studies in the UK, Ireland and the Netherlands showing that patients living in areas of socioeconomic deprivation are more likely to have BCC. Since early and small BCCs are usually easily managed with a good prognosis, prevention is preferable to treatment. People living in economically deprived areas should be informed that simple measures like avoiding extensive sun exposure or the long-term use of hats with brims can reduce the incidence of periocular skin cancers. ${ }^{10}$

\section{Clinical investigation Localization on the eyelids}

More than 20\% of the BCCs of the head and neck region emerge around the eye, with $>50 \%$ on the lower lid, $30 \%$ on the medial canthus, $15 \%$ on the upper lid and $5 \%$ on the lateral canthus. ${ }^{11}$ The infrequent involvement of the upper lid may be due to the protection by the eyebrow. ${ }^{12}$ In contrast, the frequent involvement of the lower lid may be the result of light reflection by the cornea onto the lower lid margin. Other factors such as chemical or physical irritation of tears may do more harm to the lower lid. ${ }^{4,5,8,13}$ BCCs with orbital invasion or aggressive histology occur more frequently in the medial canthus $(53.6 \%-56.2 \%)$ compared to the lower eyelid $(20.3 \%-35.7 \%)$, upper eyelid $(4.7 \%-7.1 \%)$ or lateral canthus $(3.6 \%-18.7 \%) .{ }^{14}$

\section{Manifestations of the tumor}

BCC arises from basal cells of the epidermis. It is characterized by a pearly edge and a pink color. Sometimes, it can present as ulceration and bleeding. The tumor size is positively correlated with age. The distance to the center of the tumor from the medial area is greater when the diameter is larger. ${ }^{5}$ In a large series of 56 patients with orbital invasion by periocular BCC, visible or palpable mass was found in all the patients. Other common manifestations included mass fixation to orbital bone (35.7\%), limitation of ocular motility (30.4\%) and globe displacement (17.8\%). A visible or palpable mass was observed in only $35.7 \%$ patients, with no bone fixation and no orbital signs. Other possible symptoms included immobile lids, epiphora (secondary to canalicular or nasolacrimal sac involvement) and ptosis. ${ }^{6,14}$

\section{Clinical examination}

Imaging examinations of patients with orbital invasion may find bone and soft tissue involvement. Computed tomography with bone windows can be used for visualizing bony destruction. Magnetic resonance imaging is a better option for visualizing soft tissue changes and rare perineural invasion. ${ }^{14}$

A new noninvasive imaging technique, in vivo reflectance confocal microscopy (IVCM), has sparked great interest for the diagnosis of eyelid tumors to avoid unnecessary surgical excisions. In a series of 47 cases, Cinotti et al found that IVCM had a high sensitivity (100\%) and specificity $(69.2 \%)$ for eyelid margin tumors. IVCM can be used to examine both the skin and the conjunctiva, but more studies are needed to confirm the diagnostic capabilities of this imaging technique. ${ }^{15}$

\section{Pathology}

As clinical symptoms can be variable, the final diagnosis of tumors must always be histological, and for that reason, a pathological examination is required. Biopsy is recommended for all suspicious lesions.

The histological types of BCC are superficial, infiltrating and nodular tumors, and those with adnexal differentiation. The nodular and superficial types of BCC are the most common which tend to be less aggressive. The morpheaform, infiltrating and basosquamous subtypes of BCC are more aggressive but rare (making up only $5 \%-7 \%$ of all cutaneous $\mathrm{BCCs}$ ), and have a higher rate of residual positive margins after excision, as well as a larger risk of recurrence and metastasis. Consequently, in cases of BCC with orbital invasion, these aggressive subtypes make up $>80 \%$ of cases. ${ }^{6,14}$ BCC usually presents as a single lesion with ulceration, or central scarring and peripheral keratosis, with even deep infiltration. ${ }^{3}$ Inflammation with or without the presence of ulceration increases the possibility of transformation into more aggressive tumor phenotypes. ${ }^{16}$ Long-term neglected tumors, recurrent tumors and incompletely excised tumors are factors inducing more aggressive histological types of BCC. ${ }^{8}$ Morpheaform, an aggressive histopathological type of BCC, showed a high expression of Bcl-2 (an important apoptotic gene) and moderate levels of proliferating cell nuclear antigen (a proliferation-associated marker) in a histological and immunohistochemical study of eyelid BCCs. ${ }^{17}$ Zhang et al found that telomere length was shortened and gene expression of $\mathrm{Bcl}-2$ and $\mathrm{Ki}-67$ (correlated with cell proliferation) was increased in BCC samples compared with normal tissues. ${ }^{18}$ 


\section{Treatment of periocular BCC}

We provide a brief summary of different treatment options for BCC in Table 1.

\section{Surgery}

The first treatment option for BCC is surgery, including both Mohs micrographic surgery (MMS) and wide surgical excision with frozen section margin control. ${ }^{19,20}$ Margin control is strongly recommended for cases treated with local excision. Initial treatment with local excision or MMS should achieve negative resection margins in order to reduce the risk of local recurrence. ${ }^{18}$ Treatment needs to be individualized to the patient situation, tumor characteristics and histological subtype. A cure rate of about $95 \%$ is achieved after treatment, depending on the localization, size and pathological variety of the BCC. Following surgery, the relapse rate is $1 \%-5 \%$ per year. ${ }^{3,4,5,21,22}$

The integrity of the eyelids is important for protecting and preserving the function of the globe. The distance of the tumor from the eyelid margin and the diameter of the tumor are important to estimate the prognosis and choose the best surgical technique. When the tumor affects the margin of the eyelid, reconstruction with a flap based on the tumor size in the eyelid is necessary to preserve eyelid function and esthetics (Figure 1). The aim of surgery is to excise the entire tumor (margins $>3 \mathrm{~mm}$ outside the tumor) and reestablish eyelid functionality and esthetics. The UK National Multidisciplinary Guidelines recommend that non-infiltrative BCCs $<2 \mathrm{~cm}$ should be excised with a margin of $4-5 \mathrm{~mm}$. Smaller margins $(2-3 \mathrm{~mm})$ may be taken in case of limited reconstructive options. ${ }^{23}$ The involvement of the eyelid margin makes surgical reconstruction more difficult. The smaller the size of the tumor, the simpler the reconstruction,

Table I Treatment option for periocular BCC

\begin{tabular}{ll}
\hline Treatment option & Indication \\
\hline MMS & The best choice of removing BCC on the eyelid \\
Exenteration & Bulbar or extensive orbital invasion \\
Radiotherapy & Combined with, when margins are not clear, or \\
& followed by, exenteration of high-risk histological \\
& subtype (morphoeic/infiltrative, micronodular or \\
& basosquamous) with perineural invasion \\
& An adjuvant therapy of periocular and orbital \\
Vismodegib & BCC for patients who cannot tolerate surgery or \\
& radiotherapy, or with relapsed locally advanced \\
& disease after surgery or metastatic disease \\
& A topical immunotherapy for periocular BCC, \\
IMQ & especially periocular nodular BCC \\
\hline
\end{tabular}

Abbreviations: $B C C$, basal cell carcinoma; MMS, Mohs micrographic surgery; IMQ, imiquimod. and better functional and esthetic results are obtained. ${ }^{5}$ A randomized study compared MMS to radiotherapy in 347 patients with $\mathrm{BCC}$ of $<4 \mathrm{~cm}$ size in the face. Local failure rate was $<1 \%$ in patients treated with surgery, while $7.5 \%$ in those treated with radiotherapy. Surgical patients considered their cosmetic outcome as "good" or "better" (MMS vs radiotherapy: $87 \%$ vs 69\%). This research remains the remarkable randomized study suggesting the benefit of MMS and guiding medical decision making. . $425^{25}$

Although MMS has been regarded as the best method of removing $\mathrm{BCC}$ with minimal recurrence, it may be too expensive and time-consuming for all periocular BCCs. MMS is not usually recommended for deep orbital invasion because it is always difficult to obtain correctly oriented specimens from orbital soft tissues. Also, the risk of false-negative results with standard frozen section techniques is significant. Therefore, paraffin section histology remains the choice of margin control for BCCs with orbital invasion. Reconstruction of the exenterated orbit usually uses split-thickness skin grafts, temporalis muscle flaps or free flaps. ${ }^{12,14}$ A prospective series of 1,295 patients with periocular BCC managed by MMS using fresh-frozen tissue sections was examined in Australia between 1993 and 1999. A 5-year follow-up was performed on 347 cases which had a recurrence rate of $0 \%$ and $7.8 \%$ for primary and recurrent tumors, respectively. The results confirmed MMS as the treatment of choice for periocular BCC. ${ }^{19,26}$

Ho et al conducted the largest series of $\mathrm{BCC}$ excisions with the non-Mohs rapid paraffin technique. They first performed excision with a $3 \mathrm{~mm}$ margin from the perceived edge of the lesions to obtain a rapid-turnaround paraffin section. The reconstruction was performed a few days after the histology results were available. If the margins were clear, reconstruction was performed. If the margins were involved, further excision was performed using frozen section or paraffin examination until a clear margin was obtained, followed by reconstruction. ${ }^{13}$

Rapid fresh-frozen sections, which have been widely employed with proven efficacy, are used for margin control involving just one margin not of morpheaform, but are less accurate than paraffin sections. ${ }^{13}$ Monitoring of surgical margins with frozen sections during the operation, or later paraffin sections can be useful. The surgeon can repair the surgical defect after obtaining clear margins, resulting in a better long-term cure. Conway et al evaluated the recurrence of primary $\mathrm{BCC}$ infiltrating the eyelid margins after resection with and without intraoperative frozen section (IFS) control. A total of 145 patients with a minimum 5-year follow-up were 

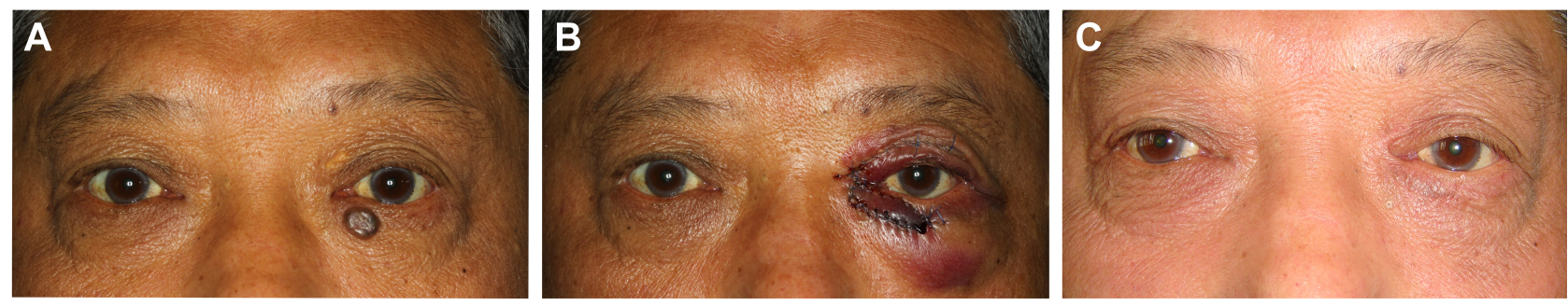

Figure I A patient with BCC on the left lower lid.

Notes: (A) The appearance of the tumor before surgery. (B) One day after MMS surgery and reconstruction with a flap of upper lid. (C) Three months after surgery. Written informed consent for publication of photographs was obtained from the patient.

Abbreviations: BCC, basal cell carcinoma; MMS, Mohs micrographic surgery.

separated into group I ( $\mathrm{n}=114$, with IFS control) and group II ( $\mathrm{n}=31$, without IFS control). There was no tumor relapse in group I compared with three $(9.7 \%)$ in group II. ${ }^{27}$

Tumors of more aggressive histological subtypes are more likely to be incompletely excised, especially when unmonitored excision is performed. Exenteration is considered in cases of bulbar or extensive orbital invasion. It may be combined with adjunctive radiotherapy when margins are not clear or in high-risk aggressive tumors with perineural invasion. ${ }^{6}$ When the lesion involves a medial canthal location, margin-controlled excision does not need to be performed at initial treatment, but when pathological analysis shows an infiltrative subtype, exenteration is strongly recommended. ${ }^{28}$ Madge et al described a case series of 20 patients with anterior orbital invasion by medial canthal BCC treated with non-exenterating surgery. Final margins were clear in 18 of 20 patients, positive in one of 20 patients and unclear in one of 20 patients. With a mean follow-up of 38 months, only one patient relapsed. This study showed that conservative (non-exenterating) surgery with careful planning and margin control in this highly selected group of patients was able to reduce the rate of disease recurrence. ${ }^{2}$

\section{Vismodegib}

Although most BCCs are treated with surgery, there is no effective therapy for locally advanced or metastatic BCC. Vismodegib, a hedgehog pathway inhibitor, has been used as a medical or adjuvant therapy of periocular and orbital BCC to decrease tumor size. ${ }^{29}$ This oral treatment is considered for locally advanced or metastatic BCC in patients who may not be good candidates for surgery or radiotherapy or with relapsed locally advanced disease after surgery or metastatic disease, or if surgery may cause problems such as vision loss, diplopia or loss of eye or orbital structures. Vismodegib is also used to treat basal cell nevus syndrome (Gorlin syndrome), which is not amenable to surgery and involves numerous cutaneous lesions of the periocular region and face. The recommended dosage is $150 \mathrm{mg}$ per day. ${ }^{30-34}$ Alterations in hedgehog signaling are involved in the pathogenesis of basal cell nevus syndrome as well as BCC. The hedgehog signal transduction pathway plays an important role in cell proliferation, and alterations in hedgehog signaling may transform a conjunctival intraepithelial neoplasia into invasive squamous cell carcinoma. ${ }^{8}$ Vismodegib represses the hedgehog pathway by directly inhibiting the $\mathrm{G}$ protein-coupled receptor protein smoothened, which in turn suppresses the development of BCC and reduces the size of tumors among patients with basal cell nevus syndrome. . $^{31,32}$

Many studies of patients with advanced periocular BCC have shown that vismodegib is effective, but the long-term results after stopping vismodegib are still unknown. In a study by Demirci et al, four patients with orbital BCC received vismodegib as the only treatment and showed a partial response with a mean reduction of $83 \%$ in tumor size after a median of 7 months of therapy. Another two patients taking vismodegib as adjuvant therapies showed complete remission after a median of 7 months of therapy and no evidence of clinical recurrence after ceasing vismodegib for a median of 15 months. An additional two patients with extensive periocular involvement had complete clinical remission after a median of 14 months of oral treatment. ${ }^{22}$ In another study, Gill et al reported the results of vismodegib administration in seven patients with advanced periocular or orbital BCC treated for a mean duration of 11 weeks. All seven cases had demonstrated recurrent tumors previously excised with controlled margins by frozen section or MMS. The mean follow-up duration of this study was 7.3 months. Two (29\%) patients had complete remission, two (29\%) patients had partial clinical regression $>80 \%$, two patients had partial clinical regression $<35 \%$ and one (14\%) patient showed disease progression. ${ }^{35}$ Finally, Papastefanou and René reported a case of advanced recurrent periocular BCC. The periorbital tumor regressed after treated with vismodegib for 
3 months but recurred after 9 months due to drug resistance and was finally treated with orbital exenteration. Resistance to vismodegib does pose a challenge in the clinic. ${ }^{36}$

The first histopathological description of the effects of vismodegib treatment on BCC was described in a case by Kahana et al. After 5 months of treatment with vismodegib, residual squamous cells not only exhibited degenerative cytologic features, but the surgical specimen failed to show nuclear immunoreactivity for the proliferation marker Ki-67. ${ }^{37}$

Side effects of vismodegib include muscle spasms, alopecia, dysgeusia, dysosmia, weight loss, fatigue, nausea, decreased appetite, diarrhea and even keratoacanthoma and squamous cell carcinoma. Although some patients give up therapy with vismodegib because of these side effects, vismodegib is generally well tolerated with acceptable side effects. Additional study will be required to better estimate the risks of treatment and to establish the treatment criteria. $^{22,31-35}$

\section{Radiotherapy}

Radiotherapy is used as an adjunctive therapy to excision with clear margins, but may be followed by exenteration of high-risk aggressive $\mathrm{BCC}$ with perineural invasion or applied to residual inoperable tumors. It is also used for BCC patients who are unsuitable surgical candidates. Radiotherapy has side effects including dry eye, cataract formation, ectropion, stenosis of the lacrimal duct, neovascular glaucoma, radiation retinopathy and radiation optic neuropathy, and can even cause significant ocular morbidity or blindness. About $25 \%$ of patients undergo radiation therapy alone for invasive orbital BCC relapse. ${ }^{6,14}$ Pontoriero et al reported a 73-year-old man with recurrent BCC in the inner canthus of the left eye extending to the extrinsic muscles of the orbit and periorbital fat. He was treated with CyberKnife in stereotactic body radiation therapy modality alone. After the treatment, the patient enjoyed rapid tumor regression, with complete remission after 6 months without toxicity. ${ }^{38}$

\section{Imiquimod (IMQ)}

Although surgical excision is the gold standard for periocular nodular BCC (PNBCC) and is associated with the highest cure rates, for those for whom surgery is not possible, topical immunotherapy may be an alternative treatment for periocular BCC. IMQ is an immune modulator which stimulates innate and adaptive immunity and induces apoptosis in tumor cells. Numerous studies have reported the use of IMQ in a $5 \%$ cream for nodular BCC. It is typically applied once per day, five times per week for 8-16 weeks depending on the patient situation. The symptoms of periocular BCC, including conjunctival irritation, conjunctivitis, keratitis, foreign body sensation, lacrimation, low visual acuity, ectropion and discomfort with blinking, usually disappear when treatment ends. ${ }^{39-44}$ A clinical study consisting of 19 patients evaluated the efficacy of topical immunotherapy with 5\% IMQ cream for the treatment of PNBCC. The histological clearance rate was $89.5 \%$ at 3 months and $84.2 \%$ at 39.5 months. The 3 -year histological clearance rate for lesions $<10 \mathrm{~mm}$ was $100 \%$ and $81.8 \%$ for lesions $>10 \mathrm{~mm} .{ }^{36}$ In another study of 15 patients with PNBCC, histopathological remission was observed in all patients after 3 months of IMQ treatment and clinical remission at 24 months of follow-up. ${ }^{40}$ In a smaller study of ten patients with PNBCC lesions, 80\% showed clinical and histological progress and remained asymptomatic for 11.7 months on average. ${ }^{45}$ Garcia-Martin et al compared the efficacy, cosmetic results and tolerance of 5\% IMQ cream and radiotherapy used to treat PNBCC. In the IMQ group, all 15 patients had complete clinical clearance at 24 months of follow-up. Another 12 patients in the radiotherapy group, who received treatment two or three times per week for 5 weeks with a dose of $300 \mathrm{cGy}$ per session and a total administered dose of 4,000-7,000 cGy, were in clinical remission at the final evaluation at 24 months. Esthetic and functional results were superior in the IMQ group, but the treatments were tolerated better in the radiotherapy group. ${ }^{46}$

\section{Factors affecting recurrence}

The risk of recurrence of BCC after surgery is estimated at $5 \%-15 \%{ }^{11,47}$ In a Spanish study, the recurrence rate after surgery with histologically clear resection margins was $5 \%{ }^{5}$ The rate of recurrence of $\mathrm{BCC}$ depends on the location, size, extent of infiltration, the histological type and the first treatment. Most recurrences occur on the lower lid and in the medial canthus, possibly related to earlier deep extension. Aggressive histological forms of $\mathrm{BCC}$ are associated with a high risk of recurrence, usually because of incomplete excision of these lesions. The more aggressive is the histological type of BCC, the higher is the risk of relapse. In a 5-year review of periocular $\mathrm{BCC}$, none of the patients with primary nodular BCC suffered recurrences, but the recurrence rate of primary morpheaform and infiltrative $\mathrm{BCC}$ reached $3.8 \%{ }^{13}$ Recurrences may become more aggressive, sometimes with transformation into a different histomorphological form. Perineural invasion rarely occurs in BCCs, and tumors with perineural invasion are usually regarded as more aggressive and are associated with higher rates of recurrent disease. 
Recurrence rate has been reported as $1 \%$ for $\mathrm{BCCs}$ and $3 \%$ for more aggressive forms of BCC. The recurrence rate of periorbital BCC after exenteration may be lower than local excision or radiotherapy alone. ${ }^{14}$

Patients with primary nodular BCC may be discharged after one 6-month follow-up once complete excision is confirmed, while patients with infiltrative, morpheaform, micronodular, mixed or recurrent BCC should be followed up for at least 5 years. All patients are advised to monitor for new lesions elsewhere. ${ }^{13}$

Assay of Ki-67 expression, which is simple and repeatable, is recommended for evaluation of proliferative activity of malignant neoplasms. In most cases, the values of the $\mathrm{Ki}-67$ index are higher in relapsed BCCs than in primary BCCs. Ki-67 may thus be a prognostic marker of BCC. ${ }^{21}$

\section{Future perspective}

Larger studies with longer follow-up are required to better understand the long-term outcomes in patients treated with different modalities. The mechanism of BCC should be further studied in order to discover additional treatment options for patients unable to undergo surgery. The results of adjunctive radiotherapy, vismodegib and 5\% IMQ cream will also require further studies to evaluate their long-term effects.

\section{Acknowledgments}

This work was supported by the Scientific Research Program of the National Health and Family Planning Commission of China (201402014), the National Natural Science Foundation of China (grants 81372469), the SMC-ChenXing Yong Scholar Program (2016, Class A), the Shuguang Program (2016) from Shanghai Municipal Education Commission. The funders played no role in the study design, data collection and analysis, decision to publish, or preparation of the manuscript.

\section{Disclosure}

The authors report no conflicts of interest in this work.

\section{References}

1. Saleh GM, Desai P, Collin JR, Ives A, Jones T, Hussain B. Incidence of eyelid basal cell carcinoma in England: 2000-2010. Br J Ophthalmol. 2017;101(2):209-212.

2. Madge SN, Khine AA, Thaller VT, et al. Globe-sparing surgery for medial canthal basal cell carcinoma with anterior orbital invasion. Ophthalmology. 2010;117(11):2222-2228.

3. Sun MT, Wu A, Huilgol SC, Selva D. Accuracy of biopsy in subtyping periocular basal cell carcinoma. Ophthal Plast Reconstr Surg. 2015; 31(6):449-451

4. Allali J, D'Hermies F, Renard G. Basal cell carcinomas of the eyelids. Ophthalmologica. 2005;219(2):57-71.
5. Pfeiffer MJ, Pfeiffer N, Valor C. Estudio descriptivo sobre el carcinoma basocelular en el párpado [Descriptive study on basal cell eyelid carcinoma]. Arch Soc Esp Oftalmol. 2015;90(9):426-431. Spanish [with English abstract].

6. Leibovitch I, McNab A, Sullivan T, Davis G, Selva D. Orbital invasion by periocular basal cell carcinoma. Ophthalmology. 2005;112(4): 717-723.

7. Situm M, Buljan M, Bulat V, Lugović Mihić L, Simić D. The role of UV radiation in the development of basal cell carcinoma. Coll Antropol. 2008;32(Suppl 2):167-170.

8. Celebi AR, Kiratli H, Soylemezoglu F. Evaluation of the 'Hedgehog' signaling pathways in squamous and basal cell carcinomas of the eyelids and conjunctiva. Oncol Lett. 2016;12(1):467-472.

9. de Gruijl FR, van Kranen HJ, Mullenders LH. UV-induces DNA damage, repair, mutations and oncogenic pathways in skin cancer. J Photochem Photobiol B. 2001;63(1-3):19-27.

10. Lim LT, Agarwal PK, Young D, Ah-Kee EY, Diaper CJ. The effect of socio-economic status on severity of periocular basal cell carcinoma at presentation. Ophthal Plast Reconstr Surg. 2015;31(6): 456-458.

11. Furdová A, Horkovičová K, Babál P, Kobzová D, Ondrušová M. Nemelanómové nádory kože mihalníc a vnútorného kútika - bazocelulárny karcinóm [Non-melanotic tumors of the eyelids skin and inner cornerbasocellular carcinoma]. Cesk Slov Oftalmol. 2015;71(6):293-301. Czech [with English abstract].

12. Echchaoui A, Benyachou M, Houssa A, et al. Prise en charge des carcinomes des paupières: étude bicentrique rétrospective sur 64 cas avec revue de littérature [Management of eyelid carcinomas: retrospective bicentric study of 64 cases and review of the literature]. J Fr Ophtalmol. 2016;39(2):187-194. French [with English abstract].

13. Ho SF, Brown L, Bamford M, Sampath R, Burns J. 5 years review of periocular basal cell carcinoma and proposed follow-up protocol. Eye (Lond). 2013;27(1):78-83.

14. Sun MT, Wu A, Figueira E, Huilgol S, Selva D. Management of periorbital basal cell carcinoma with orbital invasion. Future Oncol. 2015; 11(22):3003-3010.

15. Cinotti E, Perrot JL, Campolmi N, et al. The role of in vivo confocal microscopy in the diagnosis of eyelid margin tumors: 47 cases. $\mathrm{J} \mathrm{Am}$ Acad Dermatol. 2014;71(5):912-918.e2.

16. Tzoutzos K, Batistatou A, Kitsos G, Liasko R, Stefanou D. Retrospective clinicopathological study of 129 cancerous and 18 precancerous lesions of the eyelids in North-Western Greece. Int Ophthalmol. 2017; 37(1):203-208.

17. Bălăşoiu AT, Mănescu MR, Bălăşoiu M, et al. Histological and immunohistochemical study of the eyelid basal cell carcinomas. Rom J Morphol Embryol. 2015;56(Suppl 2):803-810.

18. Zhang L, Huang X, Zhu X, et al. Differential senescence capacities in meibomian gland carcinoma and basal cell carcinoma. Int $J$ Cancer. 2016;138(6):1442-1452.

19. Malhotra R, Huilgol SC, Huynh NT, Selva D. The Australian Mohs database, part I: periocular basal cell carcinoma experience over 7 years. Ophthalmology. 2004;111(4):624-630.

20. Harvey DT, Taylor RS, Itani KM, Loewinger RJ. Mohs micrographic surgery of the eyelid: an overview of anatomy, pathophysiology, and reconstruction options. Dermatol Surg. 2013;39(5):673-697.

21. Iljin A, Zieliński T, Antoszewski B, Sporny S. Clinicopathological analysis of recurrent basal cell carcinoma of the eyelid. Postepy Dermatol Alergol. 2016;33(1):42-46.

22. Demirci H, Worden F, Nelson CC, Elner VM, Kahana A. Efficacy of vismodegib (Erivedge) for basal cell carcinoma involving the orbit and periocular area. Ophthal Plast Reconstr Surg. 2015;31(6):463-466.

23. Newlands C, Currie R, Memon A, Whitaker S, Woolford T. Nonmelanoma skin cancer: United Kingdom National Multidisciplinary Guidelines. J Laryngol Otol. 2016;130(S2):S125-S132.

24. Avril MF, Auperin A, Margulis A, et al. Basal cell carcinoma of the face: surgery or radiotherapy? Results of a randomized study. $\mathrm{Br} J$ Cancer. 1997;76(1):100-106. 
25. Koyfman SA, Cooper JS, Beitler JJ, et al. ACR Appropriateness Criteria(®) aggressive nonmelanomatous skin cancer of the head and neck. Head Neck. 2016;38(2):175-182.

26. Malhotra R, Huilgol SC, Huynh NT, Selva D. The Australian Mohs database, part II: periocular basal cell carcinoma outcome at 5-year follow-up. Ophthalmology. 2004;111(4):631-636.

27. Conway RM, Themel S, Holbach LM. Surgery for primary basal cell carcinoma including the eyelid margins with intraoperative frozen section control: comparative interventional study with a minimum clinical follow up of 5 years. Br J Ophthalmol. 2004;88(2):236-238.

28. Iuliano A, Strianese D, Uccello G, Diplomatico A, Tebaldi S, Bonavolontà $\mathrm{G}$. Risk factors for orbital exenteration in periocular basal cell carcinoma. Am J Ophthalmol. 2012;153(2):238-241.e1.

29. Dirix L, Rutten A. Vismodegib: a promising drug in the treatment of basal cell carcinomas. Future Oncol. 2012;8(8):915-928.

30. Yin VT, Pfeiffer ML, Esmaeli B. Targeted therapy for orbital and periocular basal cell carcinoma and squamous cell carcinoma. Ophthal Plast Reconstr Surg. 2013;29(2):87-92.

31. Yin VT, Merritt H, Esmaeli B. Targeting EGFR and sonic hedgehog pathways for locally advanced eyelid and periocular carcinomas. World J Clin Cases. 2014;2(9):432-438.

32. Macha MA, Batra SK, Ganti AK. Profile of vismodegib and its potential in the treatment of advanced basal cell carcinoma. Cancer Manag Res. 2013;5:197-203.

33. Sekulic A, Migden MR, Oro AE, et al. Efficacy and safety of vismodegib in advanced basal-cell carcinoma. $N$ Engl J Med. 2012;366(23): 2171-2179.

34. Erdem GU, Sendur MA, Ozdemir NY, Yazıc1 O, Zengin N. A comprehensive review of the role of the hedgehog pathway and vismodegib in the management of basal cell carcinoma. Curr Med Res Opin. 2015; 31(4):743-756.

35. Gill HS, Moscato EE, Chang AL, Soon S, Silkiss RZ. Vismodegib for periocular and orbital basal cell carcinoma. JAMA Ophthalmol. 2013; 131(12):1591-1594.

36. Papastefanou VP, René C. Secondary resistance to vismodegib after initial successful treatment of extensive recurrent periocular basal cell carcinoma with orbital invasion. Ophthal Plast Reconstr Surg. Epub 2015 Sep 21.
37. Kahana A, Worden FP, Elner VM. Vismodegib for eye-threatening orbital basal cell carcinoma. JAMA Ophthalmol. 2013;131(10):1364-1366.

38. Pontoriero A, Iatì G, Conti A, et al. Treatment of periocular basal cell carcinoma using an advanced stereotactic device. Anticancer Res. 2014; 34(2):873-875.

39. de Macedo EM, Carneiro RC, de Lima PP, Silva BG, Matayoshi S. Imiquimod cream efficacy in the treatment of periocular nodular basal cell carcinoma: a non-randomized trial. BMC Ophthalmol. 2015;15:35.

40. Garcia-Martin E, Idoipe M, Gil LM, et al. Efficacy and tolerability of imiquimod $5 \%$ cream to treat periocular basal cell carcinomas. J Ocul Pharmacol Ther. 2010;26(4):373-379.

41. Blasi MA, Giammaria D, Balestrazzi E. Immunotherapy with imiquimod 5\% cream for eyelid nodular basal cell carcinoma. Am J Ophthalmol. 2005;140(6):1136-1139.

42. Choontanom R, Thanos S, Busse H, Stupp T. Treatment of basal cell carcinoma of the eyelids with 5\% topical imiquimod: a 3-year follow-up study. Graefes Arch Clin Exp Ophthalmol. 2007;245(8):1217-1220.

43. Prokosch V, Thanos S, Spaniol K, Stupp T. Long-term outcome after treatment with $5 \%$ topical imiquimod cream in patients with basal cell carcinoma of the eyelids. Graefes Arch Clin Exp Ophthalmol. 2011; 249(1):121-125

44. Leppälä J, Kaarniranta K, Uusitalo H, Kontkanen M. Imiquimod in the treatment of eyelid basal cell carcinoma. Acta Ophthalmol Scand. 2007;85(5):566-568.

45. Carneiro RC, de Macedo EM, Matayoshi S. Imiquimod 5\% cream for the treatment of periocular basal cell carcinoma. Ophthal Plast Reconstr Surg. 2010;26(2):100-102.

46. Garcia-Martin E, Gil-Arribas LM, Idoipe M, et al. Comparison of imiquimod 5\% cream versus radiotherapy as treatment for eyelid basal cell carcinoma. Br J Ophthalmol. 2011;95(10):1393-1396.

47. Szewczyk MP, Pazdrowski J, Dańczak-Pazdrowska A, et al. Analysis of selected recurrence risk factors after treatment of head and neck basal cell carcinoma. Postepy Dermatol Alergol. 2014;31(3):146-151.
OncoTargets and Therapy

\section{Publish your work in this journal}

OncoTargets and Therapy is an international, peer-reviewed, open access journal focusing on the pathological basis of all cancers, potential targets for therapy and treatment protocols employed to improve the management of cancer patients. The journal also focuses on the impact of management programs and new therapeutic agents and protocols on

\section{Dovepress}

patient perspectives such as quality of life, adherence and satisfaction. The manuscript management system is completely online and includes a very quick and fair peer-review system, which is all easy to use. Visit http://www.dovepress.com/testimonials.php to read real quotes from published authors. 